\title{
Presentations from the 10th International Conference on Zebrafish Development and Genetics, Madison, Wisconsin, June 20-24, 2012
}

STEM Lab: Open Lab for Novel, Student-Led Science Exploration in the Public Schools

Michael P. Ekker, Gregory J. Nathan, Xiuqi Cao, and Charlie Enriquez-Sarano

STEM Society, a Division of InSciEd Out, Century High School, Rochester, Minnesota.

\begin{abstract}
STEM (Science, Technology, Engineering and Mathematics) is becoming a crucial portion of education in America. According to the U.S. Department of Education, 16 of the 30 fastest growing occupations require STEM skills. Currently, while students might take courses in school that cover STEM subjects, opportunities to apply their knowledge independently outside the classroom are limited by time and resources. STEM Society is a student-led high school organization that seeks to increase opportunities for scientific investigation for K-12 Rochester Public Schools students. In an initial, open-ended survey conducted by STEM Society, 42\% of 109 Rochester Public School students from grades 6-12 specifically requested more "hands-on activities" and "applicable activities" to be included with their science education. STEM Society is servicing the students' requests by offering an open lab, called STEM Lab, in which students can apply their education through workshops and projects. STEM Lab offers different science equipment zones as well as leadership opportunities to Rochester Public Schools' students as they develop projects with and act as mentors to younger students. STEM Lab promotes student-to-student collaboration, as teamwork is crucial in the science community. STEM Society is working with the ongoing STEM Village component of the InSciEd Out Foundation (Integrated Science Education Outreach), a partnership between Mayo Clinic, Winona State University and Rochester Public Schools to improve science education for the 21st century. STEM Society has already secured three research grants for its inaugural STEM Lab at Kellogg Middle School, and STEM Society is repairing, refurbishing, and repurposing other equipment for STEM Lab. Through supporting STEM Village and expanding STEM Lab, STEM Society aims to foster scientific interest and motivation via student-to-student collaboration that will be retained by students throughout their higher education.
\end{abstract}

\section{InSciEd Out Aquatic Habitat Oversight for K-12 Schools}

Megan Sikkila, ${ }^{1}$ Greg E. Goodnow, ${ }^{2}$ Gary L. Moulder, ${ }^{3}$ David P. Argue, ${ }^{3}$ James Kulzer, ${ }^{4}$ Chris Pierret, ${ }^{3}$ and Stephen C. Ekker ${ }^{3}$

${ }^{1}$ University of Minnesota-Rochester, Rochester, Minnesota.

${ }^{2}$ Fish \& Pets, Rochester, Minnesota.

${ }^{3}$ Biochemistry and Molecular Biology, Mayo Clinic, Rochester, Minnesota.

${ }^{4}$ Lincoln K-8 Choice School, Rochester, Minnesota.

\begin{abstract}
Integrated Science Education Outreach (InSciEd Out) is a program designed to improve science education in schools. Zebrafish are being introduced as a component of this program. InSciEd Out has had great success, but maintaining healthy offsite tanks and fish has imposed some challenges. A student- and teacher-based program, modeled after the large Mayo Clinic Zebrafish Core Facility, but scaled to the school operation, will be introduced to the partner schools to enhance fish viability. Appropriate instruction and examples of new tank set-up are crucial to the future of fish habitats at partner schools.

Through InSciEd Out, the Aquatics Outreach Management $(\mathrm{AOM})$ program has been created to ensure that regulatory maintenance, health, and documentation is sustained for aquatic habitats at partner school sights. AOM's primary goal is to promote tank management while instilling responsibility and leadership in the teams assigned to implementation of the program. Lincoln K-8 Choice School, InSciEd Out's initial partner, has developed a process of student testing and oversight and is implementing classroom teacher training for those who choose to house zebrafish for classroom science.

The Mayo Clinic Zfishbook (http://www.zfishbook.org) has been individualized to create the InSciEd Out Chemistry Testing Report. This will allow classroom teams to document essential qualities such as $\mathrm{pH}$, conductivity, and ammonia levels for each habitat. InSciEd Out Chemistry Testing Report permits specialists at the Department of Biochemistry and Molecular Biology, Mayo Clinic, to monitor habitat values specific to individual schools easily and effectively. Classroom Chemical Response Teams (CRTs) are trained at each school to oversee the habitats and data collection. Together, Mayo Clinic and CRT teams can respond appropriately to values found outside of acceptable parameters. These teams receive rich pre-chemistry experience that will certainly benefit them in their growth as young scientists and skilled observers of nature.
\end{abstract}

\section{Students Extend Scientific Knowledge with InSciEd Out}

Skyler C. Bailey, ${ }^{1, *}$ Amber R. Godfrey, ${ }^{1, *}$ Sophia E. Goettke, ${ }^{1, *}$ Benjamin A. Jurgensen, ${ }^{1, *}$ Nolan T. Kerr, ${ }^{1, *}$ Chok Koth, ${ }^{1, *}$ Aaron K. Mead, ${ }^{1, *}$ Allison M. Schroeder, ${ }^{1}$

Anna M.R. Schornack, ${ }^{1, *}$ and Team InSciEd Out ${ }^{2}$

${ }^{1}$ Lincoln K-8 Choice School, Rochester, Minnesota.

${ }^{2}$ Integrated Science Education Outreach, Rochester, Minnesota.

*These students contributed equally. 


\section{Abstract}

One of the biggest opportunities for improvement at Lincoln K-8 Choice School, the first partner of Integrated Science Education Outreach (InSciEd Out), was in the area of Nature of Science. Analysis of Minnesota Comprehensive Assessment questions and scores with teacher teams revealed that goals and assessments for science rarely focused on cognitive capacities beyond basic recall of facts. Curriculum prior to InSciEd Out did not include the latitude for students to ask and answer their own questions. Such a restrictive framework is not conducive to student learning of the process, nature, and philosophy of science.

Within the current partnership with InSciEd Out, at grade levels where experimental design has been introduced (post grade 4), students build on current knowledge of the material with a novel question and experimentation. With this work, teacher and scientist mentorship is used to support the work, but the experimental design and practice are student-led. In earlier grade levels, student inquiry has more teacher guidance. The synthesis projects (those where students experiment to add to what is known) are referred to collectively as extensions. Following partnership with InSciEd Out, the school-wide changes at Lincoln K-8 School have been substantial, as demonstrated by both changes in science culture and improvements in science learning.

Some common themes emerged for student projects that resulted within InSciEd Out curriculum modules in the classroom. These themes included studies of addiction (with caffeine, nicotine, and alcohol) and water quality. Additionally, students were allowed to follow questions independent of classroom curriculum. Student work from Lincoln students ranged in topic from school bus bullying to tissue regeneration in zebrafish. $83 \%$ of Lincoln students in grades 6-8 extended scientific knowledge and shared their work at regional science fairs up from an average of $11 \%$ or less in years prior to InSciEd Out.

\section{Mathematical Modeling of Zebrafish Development}

Austin S. McCoy, ${ }^{1}$ Stephanie E. Westcot, ${ }^{2}$ and Chris Pierret ${ }^{2}$

${ }^{1}$ Friedell Middle School, Rochester, Minnesota.

${ }^{2}$ Biochemistry and Molecular Biology, Mayo Clinic, Rochester, Minnesota.

\section{Abstract}

Mathematical models can be used to describe life events. The goal of our work was to determine how these models fit a living system. Exponential models are often used to describe cell growth. In a system where cell division is not synchronous, the number of cells at any given time is likely well-described by exponential growth. However, in early zebrafish development, cell division is "in sync," such that total cell number increases by specific steps ( 1 cell, 2 cells, 4 cells, 8 cells, etc.). We monitored early zebrafish development and drew each of the distinct stages through 256 cells. The exponential model did not appropriately correspond to the observations, as it appeared to indicate the presence of stages not found in development (5-cell stage). We designed a stair-step model and accompanying equation that much better described this series of discrete, synced events.

Next, we harvested DNA at multiple stages to determine if a linear relationship exists between cell number and extracted DNA. More DNA/cell was extracted during the earliest hours of development, indicating that the increasing complexity of the zebrafish embryo may decrease the success of DNA extraction.

Our last experiment studied inheritance of traits in Glofish. Wildtype zebrafish females were bred with Glofish males containing an unknown number of the "Glo" transgenic concatemer. Over 600 offspring were examined under a fluorescent microscope. The number and percentage of offspring inheriting the fluorescent trait were calculated. Expected outcomes were determined based on 1, 2, and 3 transgenic inclusions independently inherited through Mendelian genetics. A goodness-of-fit statistical model was used to determine whether the observed fish phenotypes (offspring) significantly differed from the expected phenotypes. No statistically significant differences were found, suggesting that a statistical model of genetic inheritance in zebrafish is reasonable; and in our work each Glofish showed evidence of only one transgenic inclusion.

\section{Prescription Education: A Healthy Community Through Student-Led Science}

Tyler H. Koep, ${ }^{1}$ W. Charles Huskins, ${ }^{2}$ Chris Pierret, ${ }^{3}$ and Stephen C. Ekker ${ }^{3}$

${ }^{1}$ Center for Translation Science Activities, Mayo Graduate School, Rochester, Minnesota.

Departments of ${ }^{2}$ Pediatric and Adolescent Medicine, and ${ }^{3}$ Biochemistry and Molecular Biology, Mayo Clinic, Rochester, Minnesota.

\section{Abstract}

Current education practices evaluate success through overt displays of student engagement and standardized science literacy. However, the goal of improved science education is to advance individual health behavior decision making. Therefore, there remains a need to relate student engagement and science literacy to outcomes of human health. The World Health Organization stresses that health promotion requires an association between education and community engagement within the context of disease. We hypothesize that active student inquiry of relevant health concerns will empower behaviors improving life-long personal and community health. InSciEd Out's Prescription Education promises to bridge the gap between education and science as mechanisms of disease prevention. Our early work investigated the relationship between influenza and absolute humidity in schools, leading to the development of curriculum aimed at limiting infectious disease. Outcome assessments include vaccination rates and hygienic behavior, along with overall interest and science proficiency. Global partnering is currently being formatted to include school-based investigations of water quality and parasitic infection, cancer, addiction, obesity, and women's health. Zebrafish enable us to communicate concepts in a variety of diseases, serving as a model of human health processes. For example, students given the opportunity to ask their own questions about the role of nicotine in addiction neurobiology within zebrafish will be more able to readily recognize disease outcomes associated with smoking, such as lung cancer and heart disease. Our educational model provides a novel context to understand and improve human health behavior and appoints the student as the catalyst for education and disease prevention. 
The Role of Generative Dialogue in Improving Science Literacy in Schools

Jean E. Leicester

Independent Education Consultant, Winona, Minnesota.

\section{Abstract}

In a private/public partnership, a unique approach to scientific discourse is being implemented in schools as an alternative to argumentation. This approach, generative dialogue, includes a goal to hear all voices without argumentation's requirement of consensus on a singular "right" answer.

InSciEd Out (Integrated Science Education Outreach) is an innovative partnership model of science education aiming to transform the teaching and learning of science in $\mathrm{K}-12$ schools. One of the underlying aims of the partnership is the creation of a culture of learning that values diverse perspectives as an integral ingredient of all learning. Partners chose to include generative dialogue as part of the development of higher order thinking processes involved in the habits of mind of scientific reasoning and learning.

As conceived in this project, dialogue is a conscious, deliberative process of reflecting in the company of others to uncover the diversity of perspectives, beliefs, attitudes, and understandings often inherent in the meanings and prior knowledge brought to any learning experience.

As a learning tool, dialogue asks teachers and students to develop and practice higher order cognitive capacities. As a community/team building tool, dialogue fosters respectful discourse to gain deeper meaning and understanding, while at the same time building and maintaining relationships. In addition, generative dialogue is especially useful in helping students and teachers confront the emotional challenges inherent in the care and use of animals in experimentation, the nature of science in society, and more.

The relative contribution of generative dialogue to the InSciEd Out's success is as yet unknown. Certainly anecdotal evidence indicates that dialogue can be instrumental in addressing student concerns around animal experimentation. Furthermore, dialogue showed promise in addressing the inevitable conflicts and misunderstandings that arose over the last year as a result of differences in system cultures, language, perceived benefits, and expectations of the partners.

\section{Students Engaged and Learning Science Through InSciEd Out}

Corey Donack ${ }^{1}$ and Chris Pierret $^{2}$

${ }^{1}$ Lincoln K-8 Choice School, Rochester, Minnesota.

${ }^{2}$ Biochemistry and Molecular Biology, Mayo Clinic, Rochester, Minnesota.

\section{Abstract}

Lincoln K-8 Choice School in Rochester, MN, has historically delivered $8^{\text {th }}$ Grade Science Minnesota Comprehensive Assessments scores above district and state averages. However, student engagement in science was lacking. Eighteen Lincoln teachers partnered with Mayo Clinic scientists to build an authentic science curriculum utilizing zebrafish to engage students and change their perceptions regarding science education. This partnership is now known as InSciEd Out. Since partnering with InSciEd Out, student participation in regional science fair has increased from an average of $10 \%$ to $83 \%$. In fact, Lincoln now represents the deepest commitment to science fairs in our district. The next school in line has only $11 \%$ of students participating. Lincoln students have moved from $40 \%$ of students selecting the honors science track as they graduate $8^{\text {th }}$ Grade to over $85 \%$. This increase in selection of honors science has been sustained for 3 years now. Our students and teaching team have had a number of awards recognizing this work and our students are experiencing the authentic culture and practice of science. We have preliminarily found that authentic science in the classroom increases student engagement and understanding of the scientific process. Scientists being part of the classroom environment allows students to understand and relate to the work of scientists. Teachers working in a science laboratory improve their understanding of scientific process.

\section{The Role of Teaching Philosophy in Teacher Candidate Support of InSciEd Out}

Edward Kruger, ${ }^{1, *}$ Laura L. Mielke, ${ }^{1, *}$ Terry E. Sinn, ${ }^{1, *}$ Christine A. Stanich, ${ }^{1, *}$ Chris Pierret, ${ }^{2}$ and Maggie Hoody ${ }^{1}$ ${ }^{1}$ Winona State University-Rochester, Rochester, Minnesota. ${ }^{2}$ Biochemistry/Molecular Biology, Mayo Clinic, Rochester, Minnesota.

\section{Abstract}

Twenty-four students in an undergraduate program in Education participated in a 1-week internship with Integrated Science Education Outreach (InSciEd Out) in the fall of 2011. We learned about the zebrafish as a model system and were challenged to identify tasks that we could take on to support the work of teachers currently implementing curriculum developed in partnership with InSciEd Out. Our value seems rooted in the strength of our teaching philosophies.

Our philosophies of teaching consist of constructivism, social constructivism, and behaviorism. In constructivism, students are encouraged to "read the world, before they read the word". Zebrafish were used as an example when students experience cell division and the growth process. The accessibility of the zebrafish during development allowed students to "construct" an understanding of embryology on their own. Students felt their own heartbeat and then observed the heartbeat of a zebrafish under a microscope and related "if I have a heartbeat and am living, a zebrafish must be living because it has a heartbeat, too." Social constructivism allows students to deepen their understanding while learning from each other by working in groups. Examples using zebrafish include small groups creating and conducting their own experiments. Students were able to discuss why they think they did or did not have the same outcomes after performing the same experiment. Behaviorism is used in the classroom when rules need to be implemented and safety is a concern. Safety can always be a concern when students are doing scientific experimentation for the first time. When it comes to zebrafish, behaviorism is the prominent philosophy when discussing how to treat the zebrafish humanely, as required by our Institutional Animal Care and Use Committee. Students need to be taught explicitly that zebrafish are animals that need care much like our pets at home.

*These authors contributed equally. 
Teacher Candidate Role in a STEM Intervention at a Struggling Elementary School

Edward Kruger, ${ }^{1, *}$ Laura L. Mielke, ${ }^{1, *}$ Terry E. Sinn, ${ }^{1, *}$ Christine A. Stanich, ${ }^{1, *}$ and Maggie Hoody ${ }^{1}$

${ }^{1}$ Winona State University-Rochester, Rochester, Minnesota.

\section{Abstract}

Teacher candidates (students of an undergraduate Education program) created and facilitated lessons at a struggling elementary school to empower students, as well as to provide them with deeper scientific understanding. In September, teacher candidates aided lessons with fifth grade students on Bubbleology. Students tested and compared different soap brands to determine the best bubble solution, created and designed their own bubble makers, and measured the diameters of various bubbles, calculating the averages of those diameters.

Our "pet projects," each intended to enhance critical thinking and science proficiency for the participants, included Oobleck, Sound, WeDo Legos, and Secret Formulas. During the Oobleck module, students were introduced to the concept of physical properties. Students explored and experimented with a substance called Oobleck; which is a non-Newtonian substance. They participated in a convention and discussed theories of physical properties of Oobleck.

In the Sound module, students explored vibrations, sound waves, pitch, and volume through hands-on experiences. They participated in a sound walk, an interactive SmartBoard activity, making kazoos, and feeling the vibrations on musical instruments.

In the WeDo Legos module, the students became engineers, designers, and programmers while they explored with Legos. The students got a "hands-on" experience with following the instructions on building a Lego design. After they had their finished project, the students programmed their design using computer software.

In the Secret Formulas module, students worked with ingredients that they could find in their kitchens to create glue, soda, and ice cream. The students tested the glue to see which ingredients created the best glue. The students used their knowledge of the flavors of cinnamon, lime juice, and sugar to develop recipes for soda and ice cream.

Initial evaluations showed students engaged and learning in our interventions. Standardized testing scores in Science proficiency have not yet been released.

\section{Preparing Grades 4-5 to Innovate Middle School Science}

James Kulzer, ${ }^{1}$ Jared H. Nathan, ${ }^{1}$ and Michael Gobin ${ }^{2}$

${ }^{1}$ Lincoln K-8 Choice School, Rochester, Minnesota.

${ }^{2}$ Franklin Elementary School, Rochester, Minnesota.

\section{Abstract}

Lincoln K-8 Choice School's Uppers science program has partnered with Mayo Clinic scientists to build an authentic science curriculum utilizing zebrafish to engage students and change their perceptions regarding science education. This partnership is

\footnotetext{
*These authors contributed equally.
}

now known as InSciEd Out. As part of the program, teachers have gone through a summer internship to familiarize themselves with the scientific process, zebrafish, and curriculum development, with the expressed goal to improve science learning by students. Teams of fourth and fifth grade students are experiencing similar training through an internship at Lincoln K-8 Choice School. Piloted initially as an extracurricular activity for Grades 4-5 in the Spring of 2011, the internship was formalized in the fall to consist of 6 weeks wherein students learned how to operate microscopes, take digital images of embryos, maintain the care and feeding of zebrafish, and oversee zebrafish husbandry as part of the regular curriculum. Throughout this process, students were taught how to develop and use science journals to record their progress and to store data. Students met twice a week for an hour to learn about the care and feeding of zebrafish. Students were able to test water samples and make adjustments that would ensure the health and breeding potential of the fish. As a result, $60 \%$ of the students in the internship were able to successfully breed zebrafish by adjusting temperature, $\mathrm{pH}$, salinity, water volume, breeding tank style, and food intake prior to spawning. Grades $4-5$ team members at newer InSciEd Out partner, Franklin Elementary, are looking to integrate this internship to better prepare their students for middle school science.

\section{Kellogg Middle School Students Explore Population Density} with InSciEd Out

Zamzam Abu, ${ }^{1, *}$ Parth Gandhi, ${ }^{1, *}$ Kristi Quade-Wiedrich, ${ }^{1}$ David Terhaar, ${ }^{1}$ and Chris Pierret ${ }^{2}$

${ }^{1}$ Kellogg School, Rochester, Minnesota.

${ }^{2}$ Biochemistry/Molecular Biology, Mayo Clinic, Rochester, Minnesota.

\section{Abstract}

Integrated Science Education Outreach (InSciEd Out) is a collaboration formed between Mayo Clinic, Winona State University, and Rochester Public Schools (MN) with the shared vision of achieving excellence in science education. InSciEd Out employs a partnership model that includes full investment in student scientists.

Kellogg Middle School (Rochester, MN) is in its second year of partnership with InSciEd Out. Students take part in a curriculum module themed "Population Density." In this module, students explore world geography and the economic and health implications of increasing population density. Students enter into a guided inquiry experience in their science classrooms. In an experiment within the curriculum module, students observe the effects of population density on zebrafish development. They use these observations to build on current knowledge of the material with a novel, student-led question and experimentation. Student projects were intended to explore the negative outcomes of increasing population density for humans including water, air, light, and noise pollution, among other topics such as crime and social behavior.

Kellogg student projects within the module this year included exploration of water quality mediation through filtering, chemical treatment, natural filtration (snails), and nutritional supplementation of zebrafish (to oppose negative outcomes of pollution). Other students looked into additional effects of 
urbanization, including light and sound pollution, drug use, and accessibility.

Factors Influencing the Efficacy of Internships for the Professional Development of Teachers in Science

Madeleine E.M. Hammerlund, ${ }^{1}$ Maggie Hoody, ${ }^{2}$ and Chris Pierret ${ }^{3}$

${ }^{1}$ University of Minnesota-Rochester, Rochester, Minnesota.

${ }^{2}$ Education, Winona State University-Rochester, Rochester, Minnesota.

${ }^{3}$ Biochemistry and Molecular Biology, Mayo Clinic, Rochester, Minnesota.

\begin{abstract}
Integrated Science Education Outreach (InSciEd Out) is a collaboration formed between Mayo Clinic, Winona State University, and Rochester Public Schools (MN) with the shared vision of achieving excellence in science education. Teams of teachers from all disciplines within a single school experience cutting-edge science using the zebrafish model system, as well as current pedagogical methods during a 96-hour summer internship over 12 days at Mayo Clinic. The internship has gone through several permutations in the last 3 years with regard to total length, depth of teams, and total percentage of teachers within a school. An online survey tool was used to track a number of teacher outcomes including comfort in the classroom with science and availability of resources. In this work, we analyzed surveys completed before each teaching team started their internship and again after they had run new curriculum developed during the internship with their own students. The best model for growth in teacher comfort and visibility of available resources was potentially the most workintensive. In this version, we had all classroom teachers and most of the support staff attend the internship. The school that was used for that model has subsequently provided teachers opportunities for additional internships with the InSciEd Out team focusing on cultural relevance and alignment of their work across grade levels. This analysis has provided us with growth and improvement in the process of partnering with new schools. Further, we are working to describe the potential presence of a "bystander effect," the shift in comfort with science of teachers who did not attend our internship, but work closely with those who did.
\end{abstract}

\section{Elementary Students as the Producers of Science}

Kristi A. Beeman, ${ }^{1, *}$ Andreanna M. Harmon, ${ }^{1, *}$

Lisa M. Robbins, ${ }^{1, *}$ Madeleine E.M. Hammerlund, ${ }^{2}$ Chris Pierret, ${ }^{3}$ and Maggie Hoody ${ }^{4}$

${ }^{1}$ Lincoln K-8 Choice School, Rochester, Minnesota.

${ }^{2}$ University of Minnesota-Rochester, Rochester, Minnesota.

${ }^{3}$ Biochemistry and Molecular Biology, Mayo Clinic, Rochester, Minnesota.

${ }^{4}$ Education, Winona State University-Rochester, Rochester, Minnesota.

\section{Abstract}

Lincoln K-8 Choice School in Rochester, MN has historically delivered science to students in a variety of formats, including

*These authors contributed equally. standards driven curriculum, thematic curriculum, and Full Option Science System (FOSS) kits with varied results. Eighteen Lincoln teachers partnered with Mayo Clinic scientists in 2009 to build an authentic science curriculum utilizing zebrafish to engage students and change their perceptions of science and scientists. This partnership improved further through the addition of Winona State University. Thoughtful, professional dialogues along with active learning and implementation of best practices were integrated with the science curriculum modules. These modules were developed to be responsive to the diversity of our students and community. The entire partnership is now known as InSciEd Out.

Curriculum at Lincoln aligns student products with the Discourse (language and culture) of science. These products are built in a manner that is specific to each grade level with a goal of publication by young scientists. At each level, student language development and science content knowledge is tracked through the use of Talking Drawings, a method of pre/post evaluation where students use words and pictures to respond to a prompt developed by the teaching team.

Scientific experiences at Lincoln are driven by the process of inquiry. Students actively investigate questions about the world around them. Student products of this curriculum are milestones of the scientific process. They include laboratory notebooks rich with charts, graphs, tables, and illustrative drawings. Students also produce the outcomes of authentic science: oral reports, posters, and scientific papers. Scientists build relationships with students and teachers to take part in the development of scientific Discourse.

Our students and teaching teams have received a number of awards and publicity recognizing this work and our students are experiencing the authentic practice of science.

\section{A Role for Administration in Science Education Reform}

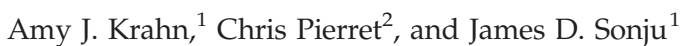

${ }^{1}$ Lincoln K-8 Choice School, Rochester, Minnesota.

${ }^{2}$ Biochemistry and Molecular Biology, Mayo Clinic, Rochester, Minnesota.

\section{Abstract}

Lincoln K-8 Choice School entered into a partnership with Integrated Science Education Outreach (InSciEd Out) in the Spring of 2009. This process has led to a cultural change within our school led by our staff and students. However, we have met challenges in the areas of time, teaching compensation and emotional needs, grant oversight, and maintenance of our vision. Our experience has identified several roles for the administration team in supporting education reform.

In many school districts, teachers have several opportunities for professional development. Staff members of Rochester Public Schools are given professional development days that are used at staff discretion. The administrative role is to ensure that teacher substitutes are secured for development days and that the corresponding paperwork is complete.

In states with teacher union contracts, stipend and pay amounts are determined based on what activities they are participating in and the amount of time they are putting forth. We have not found the dollar amount to actually change the rate of volunteerism for the program or the measure of the final product.

The administrative team must provide support for change, as change can be difficult. Administration must be first to embrace change and make it work. We coordinate the celebration of tea- 
cher and student work and consistently put our team members forward for local, regional, and national recognition awards.

Administration provides tracking support of grant funding and can be the data collector in getting deadlines met on time. The grant funding we have received has provided beneficial activities and learning for all students and staff.

These changes are maintained in our school through conscious planning of our team meetings and our designated professional development time. Those wanting to innovate science education should look to administrative partners to ensure the success of their initiatives.

\section{K-12 Student Scientific Publication Through InSciEd Out}

Linnea R. Archer, ${ }^{1}$ Corey Dornack, ${ }^{1}$ Robin G. Molella, ${ }^{2}$ David P. Argue, ${ }^{2}$ and Chris Pierret ${ }^{2}$

${ }^{1}$ Lincoln K-8 Choice School, Rochester, Minnesota.

${ }^{2}$ Biochemistry and Molecular Biology, Mayo Clinic, Rochester, Minnesota.

\section{Abstract}

Our middle school program at Lincoln K-8 Choice School, Rochester, MN, is undergoing scientific reform seeking publication for our students. Four years ago, $11 \%$ of our middle school students participated in the regional science fair. This year $83 \%$ of the students participated with $98 \%$ of middle school students completing an inquiry based research project. Previously $0 \%$ of our students published scientific papers. Our goals were to: 1) Have students create a publishable scientific journal article from their research so that $100 \%$ of students publish; and 2) Create a database of student-created scientific papers in order to facilitate further research and peer-review. Students took the information created for a poster board project in science class and reformatted it into American Chemical Society (ACS) format. In age similar groups, students selected one article to move forward for publishing, using one student's research but multiple authors of the report. With support from artists, medical professionals, and scientists, students worked as a collaborative team to select the most publishable paper (interesting, important, and novel science), edited it, ensured academic vocabulary, researched supplemental information, reformatted it per journal specifications, checked and found additional resources, and peer-reviewed it with other groups. Then articles will be submitted through an online publishing tool created with our Mayo Clinic partners. This tool has been named the next generation paper (NGP). The NGP format is designed to retain traditional elements (i.e., Abstract, Introduction, etc.). Papers are viewed using any web browser running on any computing platform, including mobile devices. The NGP format allows students to publish their work, reference others' work, and review papers anonymously; the NGP format provides a more streamlined reading experience by providing as much information to the reader inline as possible, without requiring the user to skip between pages. 